\title{
APLICAÇÃO DO PROTOCOLO DE AVALIAÇÃo RÁPIDA (PAR) PARA ANÁLISE DA DEGRADAÇÃO AMBIENTAL DO CÓRREGO TAMANDUÁ (IPORÁ-GO)
}

\author{
Katyuce Silva ${ }^{(a)}$, Diego Tarley Ferreira Nascimento ${ }^{(b)}$ \\ (a) Acadêmica do curso de Geografia da Universidade Estadual de Goiás - Campus Iporá, katysilv470@ gmail.com \\ (b) Professor do curso de Geografia da Universidade Estadual de Goiás - Campus Iporá, diego.tarley@ gmail.com
}

\section{EIXO: BACIAS HIDROGRÁFICAS E RECURSOS HÍDRICOS: ANÁLISE, PLANEJAMENTO E GESTÃO}

\begin{abstract}
Resumo
O objetivo geral do presente trabalho foi de empregar a metodologia dos Protocolos de Avaliação Rápida (PAR) para realizar uma análise preliminar do estado de degradação ambiental de dois trechos do Córrego Tamanduá, um à montante e outro a jusante da área urbana de Iporá-GO. O PAR se baseia numa avaliação qualitativa dos corpos hídricos superficiais, em que são diagnosticadas as informações de degradação do manancial de maneira fácil e rápida. Correspondendo a importante insumo à fixação e sobrevivência do homem, os corpos hídricos têm apresentado um longo histórico de degradação ambiental. No caso do Córrego Tamanduá, os dados indicam que o trecho à jusante da área urbana corresponde às piores condições de preservação, indicando a influência da população no processo de degradação ambiental desse corpo hídrico.
\end{abstract}

Palavras chave: Avaliação; Ambiental; Córrego; Tamanduá; Iporá-GO.

\section{Introdução}

Nascimento (2016) comenta que a natureza foi inicialmente entendida como o prolongamento da própria existência do homem. Com o desenvolvimento do conhecimento filosófico, passou a ser vista como um sistema mecânico onde o homem faria parte como componente, e, posteriormente, apoiada na visão religiosa e na ideologia antropocêntrica, passou a ser encarada como propriedade do homem, um recurso a ser explorado.

Sobre isso, sabe-se que, desde os primórdios, a ocupação humana se deu próxima aos corpos hídricos, uma vez que o homem depende totalmente da água para consumo, higienização e produção de alimentos. Assim, o fácil acesso e a abundante disponibilidade de água eram requisitos essenciais a fixação das populações, além da sua sobrevivência e desenvolvimento.

Em decorrência do crescimento da população e das demandas necessárias a sua sobrevivência, exploração dos recursos naturais - dentre os quais a água está inserida, tem transcorrido de forma inadequada e 
insustentável, ocasionando, assim, uma série de degradação e até mesmo o exaurimento desse recurso, além de outras consequências, tais como a poluição, desmatamento etc.

Nesse contexto, o objetivo geral do presente trabalho é empregar a metodologia dos Protocolos de Avaliação Rápida (PAR) para realizar uma análise preliminar do estado de degradação ambiental do Córrego Tamanduá, situado no município de Iporá-GO.

\section{Materiais e Métodos}

O Córrego Tamanduá está situado no município de Iporá, estando este localizado na porção oeste do estado de Goiás. O Córrego possui extensão aproximada de $8 \mathrm{~km}$ e atravessa a área urbana de Iporá antes de desaguar no Ribeirão Santo Antônio - afluente responsável pela captação de água da cidade.

O método definido no presente trabalho para avaliação preliminar do estado de degradação ambiental foi o consagrado Protocolo de Avaliação Rápida (PAR). Conforme exposto por Bizzo, Menezes e Andrade (2014), os PAR se baseiam numa avaliação qualitativa dos corpos hídricos superficiais, em que são diagnosticadas as informações de degradação do manancial de maneira fácil e rápida. Essa metodologia já foi empregada para outras localidades por Callisto et al. (2002) e Rodrigues e Castro (2008), mostrando bons resultados.

Segundo Callisto et al (2002), o PAR avalia uma série de parâmetros, pontuando-os de 0 a 4 ou de 0 a 5 , conforme o estado de degradação de cada parâmetro, sendo dada uma pontuação final a cada trecho do corpo hídrico analisado. Os autores comentam que essa pontuação final reflete o nível de preservação das condições ecológicas, determinando os locais com pontuação entre 0 a 40 como trechos impactados; de 41 a 60 pontos como trechos alterados; e acima de 61pontos condizente com trechos naturais.

Sendo assim, por se tratar de um estudo preliminar, os parâmetros foram resumidos a apenas 13 e foram avaliados apenas dois pontos do Córrego Tamanduá - indicados pela Figura 1, estando um a montante e outro a jusante de área urbana - com vistas a ver o grau de degradação que a cidade repercute ao manancial. Considerando a diminuição da quantidade dos parâmetros, os intervalos da denominação das condições ecológicas de cada trecho determinada pela soma total dos pontos também foi adaptada, ficando: 0 a 22 pontos como trechos impactados; de 23 a 34 pontos como trechos alterados; e acima de 35 pontos como trechos naturais.

\section{Resultados e Discussões}


XVII Simpósio Brasileiro de Geografia Física Aplicada

I Congresso Nacional de Geografia Física
OS DESAFIOS DA GEOGRAFIA FÍSICA NA FRONTEIRA DO CONHECIMENTO

Instituto de Geociências - Unicamp

Campinas - SP

28 de Junho à 02 de Julho de 2017

A Figura 1 demonstra os parâmetros e as condições de degradação de cada um, para os dois locais avaliados, sendo que o Ponto 1, à montante da cidade, apresentou as melhores condições de preservação do corpo hídrico, principalmente com relação à ausência de erosão e/ou assoreamento; sem alterações antrópicas; fundo do corpo hídrico composto por pedras/cascalhos; sem canalização ou dragagem e margens estáveis, conforme exposto pelas Figura 2-A. A soma da pontuação para o trecho do Ponto 1 alcançou o valor de 39, avaliando o trecho como natural.

\begin{tabular}{|c|c|c|}
\hline Parâmetro & Ponto 1 (à montante da cidade) & Ponto 2 (à jusante da cidade) \\
\hline 1 - Ocupação das margens & $\begin{array}{c}\text { Pastagem/Agricultura/Reflorestam } \\
\text { ento ( } 2 \text { pontos) }\end{array}$ & Residencial/Comercial/Industrial \\
\hline 2 - Erosão próxima e/ou assoreamento & Ausente & Moderada \\
\hline 3 - Alterações Antrópicas & Ausente & $\begin{array}{l}\text { Alterações de origem doméstica } \\
\text { (esgoto; lixo) }\end{array}$ \\
\hline 4- Cobertura Vegetal & Total & Parcial \\
\hline 5 - Odor da água & Esgoto (ovo podre) & Esgoto (ovo podre) \\
\hline 6 - Oleosidade da água & Moderada & Moderada \\
\hline 7- Transparência da água & Turva/Cor de chá-forte & Turva/Cor de chá-forte \\
\hline 8 - Tipo de fundo & Pedras/Cascalho & Pedras/Cascalho \\
\hline \multicolumn{3}{|c|}{ Legenda: 4 Pontos 2 Pontos 0 Pontos } \\
\hline 9 - alteração no canal do rio & Canalização ou dragagem ausente & Margens modificadas; acima de $80 \%$ \\
\hline 10 - Presença de mata ciliar & $\begin{array}{c}\text { Entre } 503 \text { 70\% com vegetação } \\
\text { ripária nativa }\end{array}$ & $\begin{array}{c}\text { Menos de } 50 \% \text { da mata ciliar nativa; } \\
\text { desflorestamento acentuado }\end{array}$ \\
\hline 11 - Estabilidade das margens & Margens estáveis & Instável \\
\hline 12 - Extensão da mata ciliar & Largura entre 6 e $12 \mathrm{~m}$ & $\begin{array}{l}\text { Largura da vegetação ripária menor que } \\
\qquad 6 \mathrm{~m} \\
\end{array}$ \\
\hline \multirow[t]{2}{*}{22 - Presença de plantas aquáticas } & \begin{tabular}{|c|} 
Macrófilas aquáticas ou algas \\
filamentosas, musgo abastrato com \\
perfliton
\end{tabular} & $\begin{array}{l}\text { Ausência de vegetação aquática no } \\
\text { leito }\end{array}$ \\
\hline & Legenda 5 Pontos 3 Por & ntos 2 Pontos 0 Pontos \\
\hline $\begin{array}{l}\text { Total de pontos - Nível de } \\
\text { degradação/preservação }\end{array}$ & 39 - trecho natural & 18 - trecho impactado \\
\hline
\end{tabular}

Figura 1 - Avaliação de dois trechos do Córrego Tamanduá a partir do PAR.

Elaboração: próprios autores.

No caso do Ponto 2, à justante da cidade, a situação é bem diferente, com as piores condições na maioria dos parâmetros analisados, especialmente para a ocupação das margens com uso residencial; assoreamento moderado; lançamento de esgoto e lixo; canalização do rio; pouca presença de mata ciliar, margens instáveis e ausência de plantas aquática no leito - conforme se pode ver pela Figura 2-B. A soma da pontuação foi de 18, avaliando o ponto como trecho impactado. 


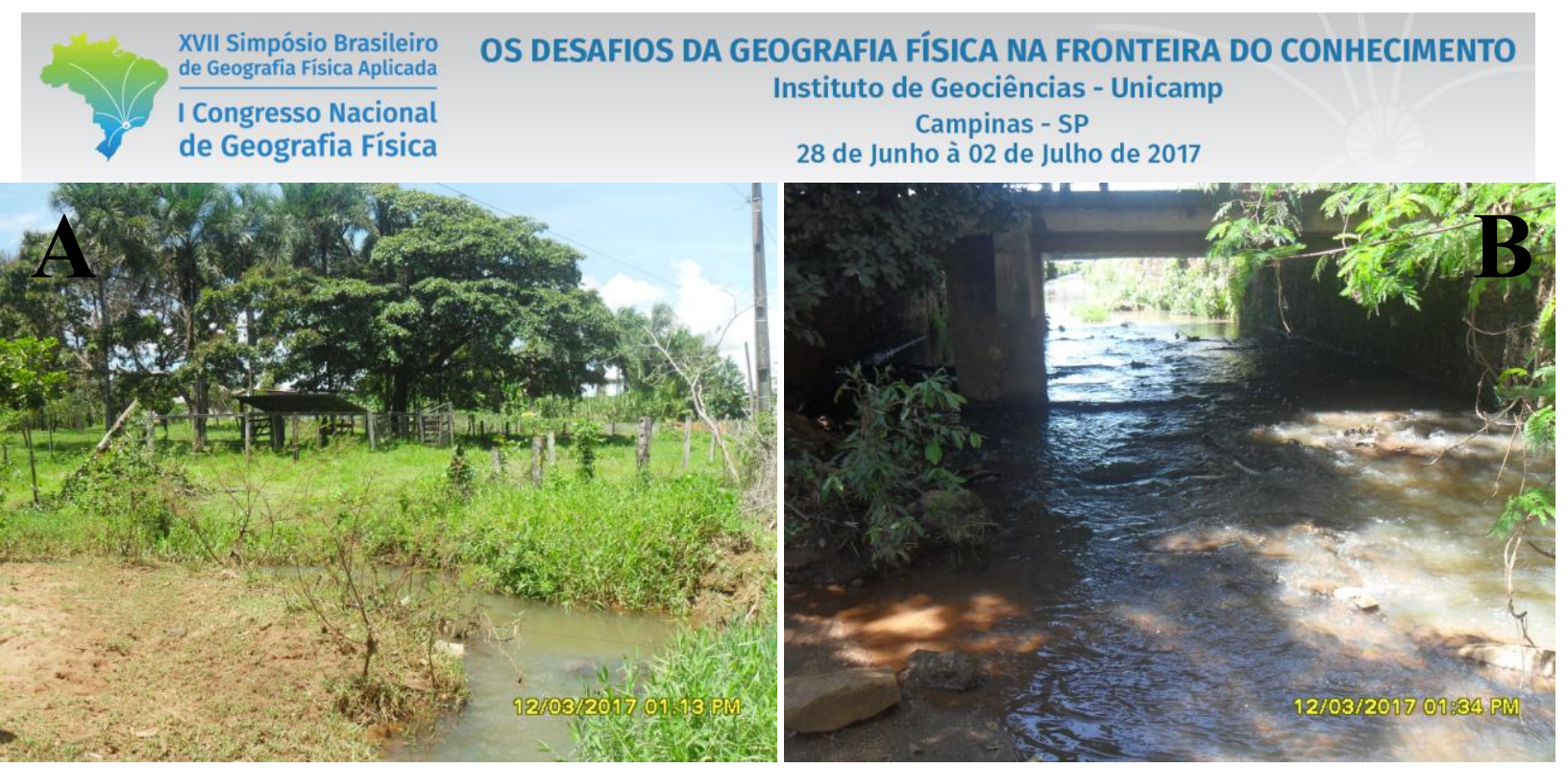

Figura 2 - Fotografias dos pontos avaliados do Córrego Tamanduá à montante (A) e jusante (B) da cidade.

Fonte: SILVA (2017).

\section{Considerações Finais}

Correspondendo a importante insumo à fixação e sobrevivência do homem, os corpos hídricos tem apresentado um longo histórico de degradação ambiental. Considerando a dificuldade de avaliações quantitativas do estado de degradação, métodos indiretos e qualitativos como os Protocolos de Avaliação Rápida se destacam como importante instrumento de análise ambiental. No caso do Córrego Tamanduá, os dados indicam que o trecho à jusante da área urbana corresponde às piores condições de preservação, indicando a influência da população no processo de degradação ambiental desse corpo hídrico.

\section{Referências}

BIZZO, M. R. de O. MENEZES, J.; ANDRADE, S. F. de. Protocolos de avaliação rápida de rios (PAR). Caderno de Estudos Geoambientais, v. 04, n. 01, p. 05-13, 2014.

CALLISTO, M., et al. Aplicação de um protocolo de avaliação rápida da diversidade de hábitats em atividades de ensino e pesquisa (MG-RJ). Acta Limnologica Brasiliensia.v. 14, n. 1, p.91-98, 2002.

NASCIMENTO, D. T. F. Relação homem-natureza e degradação ambiental: estudo de caso para o município de Goiânia-GO/Brasil. In: ENCUENTRO DE GEÓGRAFOS DE AMÉRICA LATINA, 2015, La Habana. Anais do XV Egal, 2015.

RODRIGUES, A.S.L.; CASTRO, P.T.A. Protocolos de Avaliação Rápida: instrumentos complementares no monitoramento dos recursos hídricos. Revista Brasileira de Recursos Hídricos, v. 13, n. 1, p. 161-170, 2008. 